\title{
1 IMPROVEMENT STRATEGIES IN OVINE ARTIFICIAL INSEMINATION
}

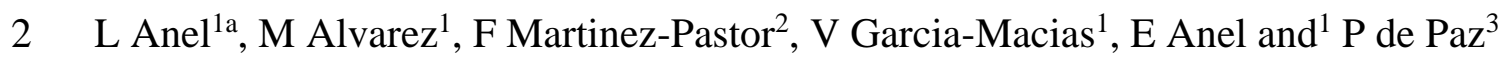

$3{ }^{1}$ Animal Reproduction and Obstetrics. University of León, 24071 Leon, Spain.

$4 \quad{ }^{2}$ Biology Reproduction. IREC, UCLM-CSIC-JCCM, 02071 Albacete, Spain.

$5 \quad{ }^{3}$ Cellular Biology and Anatomy. University of León, 24071 Leon, Spain.

6

$7 \quad{ }^{a}$ corresponding author. dsalar@unileon.es; phone 034 987291320; fax 034987291322

8 Our own data cited in the present work from experiences in milk sheep breeds. Those experiences have been 9 supported by University of León, ANCHE, Junta of Castilla y León, Diputación de Valladolid, Diputación de 10 León, Caja Burgos, CICYT (AGF93/0225, AGL2005-07601/GAN) and FEDER (1FD97-0367).

12 1.- Abstract.

13 Artificial insemination in ram is scarcely widespread comparing with other domestic 14 species. This has been due not only to fertility results being irregular and low but also 15 because of the difficulty in the application of enhancements such as the use of frozen16 thawed sperm. Although there is a lot of information on the use of different options to 17 improve these AI results (such as transcervical application, the use of thawed sperm, etc) commercial programmes can be classified on two general categories: those using

19 refrigerated semen $\left(15^{\circ} \mathrm{C}\right)$ by superficial intracervical deposition (vaginal), and, more

20 restricted, those using thawed sperm by intrauterine deposition (laparoscopy).

21 In the present work we have summarized our viewpoint on three general research lines for 22 the improvement of AI results in sheep: semen preservation, AI procedures and semen assessment. Briefly, in ram it is necessary to develop a medium term methodology of

24 sperm refrigeration (3-5 days) which would allow the distribution of sperm doses to a 25 widespread area. Nevertheless, it is also necessary to develop an intrauterine transcervical 26 AI technique which allows thawed semen to be applied by vaginal insemination. Besides, 
1 the low predictive value of classic assessment techniques limits the ability to adjust the

2 number of spermatozoa per dose according to its actual fertility.

\section{2.- Introduction.}

5 The enhancement of artificial insemination is a valuable tool in genetic improvement 6 programs and ovine breeds conservation. However, artificial insemination is not so 7 widespread in ovine as it is in other domestic species. This has been due not only to 8 fertility results being irregular and low, but also because of the difficulty in the application

9 of enhancements such as the use of frozen-thawed sperm. Insemination outcome is affected 10 by many factors (intrinsic and extrinsic) related to female (handling, seasonality, genital 11 morphology, etc), male (seasonality, sperm quality, sperm conservation, etc), farm 12 (environmental conditions, sanitary status, handling, etc) and the technique itself (route of 13 application, spermatozoa/dose, technician, etc) (Donovan et al., 2004; Paulenz et al., 2004; 14 Shackell et al., 1990).

15 In this sense, Anel et al. (2005) with data on AI in the Churra breed (Spanish milking 16 breed) showed a great difference between vaginal-cervical inseminations (refrigerated 17 sperm) and laparoscopic inseminations (thawed sperm) with regard to fertility (Table 1). 18 This difference justifies the use of laparoscopy in many cases, since it reduces the 19 detrimental influence of some sources of variation, which had a higher impact on vaginal20 cervical AI fertility. A large part of fertility variation was due to the farm factor. Good 21 handling practices and careful management of other sources of variation might help to prevent a low fertility outcome. When preparing ewe lots for AI, we recommend that ewes older than 5 years should not be used, that the lambing-AI interval should be longer than 10 weeks and that insemination should not be carried out during high-temperature periods

25 (July-August). 
1 In order to analyze the problems of AI spreading in ovine, it is necessary to know which

2 would be the most ideal conditions for application that would ensure the development of

3 the technique under optimal conditions. That is, the insemination at any time of the year

4 (seasonality problem), the use of insemination with a previous treatment of induction and

5 synchronization of oestrus, which may have a negative effects on fertility. Also, the

6 application of frozen-thawed sperm (only useful with deep intrauterine deposition) applied

7 by vaginal method -intrauterine transcervical- (the cervix structure is an obstacle when the

8 intrauterine transcervical route is being used).

9 In the present work we have summarized our viewpoint on three research lines for the

10 improvement of AI results in sheep: ram semen preservation, ovine artificial insemination

11 procedures and ram semen assessment.

13 3.- Ram semen preservation.

14 Currently, there are two methods which allow to achieve acceptable fertility results by AI 15 in ovine: cooling $\left(15^{\circ} \mathrm{C}\right)$ and freezing (laparoscopic technique). Nevertheless, ovine AI 16 fertility depends on the interaction between the sperm preservation method and the seminal 17 application technique (vaginal, cervical or intrauterine deposition). A methodological 18 problem is derived from this interaction, which hinders the widespread use of techniques 19 based on frozen-thawed ram semen. Refrigeration of samples at $5^{\circ} \mathrm{C}$ may provide a 20 solution until the problem of using thawed semen by vaginal method is solved.

22 3.1.- Storage at refrigerated temperatures.

23 The storage of semen in a liquid state can be achieved by methods that reduce the 24 metabolism of spermatozoa and thereby prolong their fertile life. Liquid storage of 25 spermatozoa is carried out using temperatures low enough to depress sperm metabolism 
$1 \quad\left(5^{\circ} \mathrm{C}\right.$ or $\left.15^{\circ} \mathrm{C}\right)$. The storage of ram spermatozoa at a low temperature significantly affects

2 cell viability due to the detrimental effects of cold shock. These effects can be partially

3 overcome by gradually cooling semen from room to storage temperature and by

4 supplementing the diluents with some additives. Also, semen storage has been carried out

5 by reversible inactivation of spermatozoa at ambient temperatures (Salamon and Maxwell,

$62000)$.

7 Many diluents have been developed to make liquid storage of semen useful for AI. At

8 present, the most useful method for intra-cervical AI (vaginal method) is the application of

9 cooled semen at $15^{\circ} \mathrm{C}$ being the fertile life of the spermatozoa 6-8 $\mathrm{h}$. However, diluted

10 semen must have a minimum shelf-life of between 2 and 4 days in order to be used in

11 distant locations. The evolution of semen dilution technology has showed that survival of

12 spermatozoa for extended periods is inversely related to their metabolic activity. Storage of

13 bull spermatozoa at $5^{\circ} \mathrm{C}$ reduces metabolic activity which contributes to extended survival.

14 Nonetheless, not all changes induced by low temperatures are beneficial to spermatozoa.

15 For instance, the intracellular concentration of $\mathrm{Na}$ rises due to the depressed activity of the

$16 \mathrm{Na}^{ \pm} / \mathrm{K}^{ \pm}$pump at $5^{\circ} \mathrm{C}$ and this effect is detrimental to the survival of spermatozoa

17 (Vishwanath and Shannon, 2000).

18 It was postulated that storage at ambient temperature may be superior to storage at $5^{\circ} \mathrm{C}$ but

19 this has resulted in lower fertility. Fertility declined rapidly when ram semen stored for

20 more than $24 \mathrm{~h}$ was used for cervical insemination (Maxwell and Salamon, 1993). The

21 lambing rates for semen stored for 24,48 and $72 \mathrm{~h}$ were $45-50 \%, 25-30 \%$ and $15-20 \%$

22 respectively, whereas the lambing rate for fresh semen was $65-75 \%$.

23 Sperm are not exposed to aerobic conditions naturally, but no special precautions are taken

24 to maintain anaerobic conditions during the processing of semen for AI. Observations on

25 the effect of a gaseous environment on sperm survival have been reported at low 
1 temperatures, where removal of oxygen was beneficial for sperm survival (Batellier et al 2 2001). Storage of semen packaged at $5^{\circ} \mathrm{C}$ in encapsulated form has been examined in the

3 ram. Encapsulated semen shows a reduced viability and acrosome integrity respect to the

4 uncapsulated control but there was no difference between both kinds regarding fertilization 5 rates (Maxwell et al, 1996).

6 The cytoplasm of somatic cells contains several antioxidant enzyme systems. However 7 sperm cells are devoid of most of their cytoplasm, and therefore have little protection 8 against ROS (Foote et al., 2002). The physiological reasons for the rapid decline in fertility 9 of spermatozoa stored at ambient temperature are presumed to be due to three factors: 10 extracellular oxidative stress, effects of the seminal plasma and endogenous free radical 11 production. In general, spermatozoa deteriorate as the duration of storage increase 12 irrespective of the diluent or temperature of storage. The motility and morphological 13 integrity of spermatozoa are negatively affected during storage and these changes affect to 14 the transport and survival of spermatozoa in the female reproductive tract and to their 15 fertility (Salamon and Maxwell, 2000).

16 Although fertility after AI can be maintained during preservation at $15^{\circ} \mathrm{C}$ for several hours, 17 prolonged preservation reduces the fertility of the spermatozoa, probably due to stress 18 during in vitro storage. The physiological processes that contribute to the aging of 19 spermatozoa upon in vitro storage need to be understood to improve their fertility 20 following AI. In fact, sperm cells are characterized by an unusual capacity to generate 21 reactive oxygen species which cause lipid peroxidation. High levels of lipid peroxidation 22 of the plasma membrane could greatly modify membrane stability leading to cell death. 23 Also, reactive oxygen species seems to impair sperm cell motility and chromatin integrity.

24 The damage of chromatin compromises the viability of the embryos. In fact, an increase in 
1 embryo mortality associated with aging of spermatozoa has been observed for several

2 species (Salamon and Maxwell, 2000).

3 Adding antioxidants (superoxide dismutase -SOD-, catalase, glutathione) to the extender

4 has improved the percentage of motile spermatozoa and acrosome integrity of spermatozoa

5 during chilled storage of bull semen (Foote et al., 2002). A combination of SOD and

6 catalase in a Tris-glucose-yolk diluent had the additional effect of improving the survival

7 of ram spermatozoa stored at $5^{\circ} \mathrm{C}$. Antioxidants such as superoxide dismutase, catalase,

8 glutathione peroxidase and cytochrome $\mathrm{C}$ improved the motility and acrosome integrity of

9 ram spermatozoa in liquid preservation, and there was a linear improvement in survival of

10 spermatozoa with increasing doses of antioxidants (Maxwell and Stojanov, 1996). In

11 recent studies, catalase was found to be beneficial to bull sperm stored at $5^{\circ} \mathrm{C}$ in egg yolk

12 extender but it did not increase sperm survival in milk-based diluents (Foote et al, 2002).

13 Success in cooled stored semen use depends on a lot of confounding factors such as

14 temperature of storage, composition of the extender, number of spermatozoa applied on

15 AI, etc. (Fernandez-Abella et al., 2003). A large variety of extenders combining various

16 components (sugar, electrolytes, buffers, egg yolk, etc) has been proposed for cooling

17 sperm (Lopez-Saez et al., 2000). Egg yolk-based extenders are known to be practical and

18 efficient in protecting ram spermatozoa during storage before AI (Paulenz at al., 2002).

19 However, an extender is a complex fluid, which contains components that may be

20 beneficial or detrimental to sperm survival. In this sense, using milk diluent to preserve

21 ram semen at $15^{\circ} \mathrm{C}$ maintains the fertilizing capacity of sperm 8-10 hours of storage (Yañiz

22 et al, 2005).

23 During storage in liquid state sperm cells will generally undergo sedimentation which can

24 cause large $\mathrm{pH}$-fluctuations and a local increase the concentration of metabolic products.

25 The solid state of storage medium could to avoid spermatozoa sedimentation reducing 
1 changes in local chemical conditions and also diminish the metabolic consumption of

2 mobile spermatozoa. In this sense, the successful storage of ram spermatozoa appears to be

3 related to reversible reducing of its metabolic activity prolonging their fertile life. To

4 increase the viscosity of the medium and thus diminish sperm motility, the addition of

5 gelatine has been assessed in several species (Yañiz et al., 2005).

6 The use of cooled semen has the advantage of being easy to handle, cheap and can be used

7 for cervical insemination. However, inadequate semen preservation is still an obstacle for

8 the extensive use of cooled semen in sheep AI programs. The rate of temperature descent

9 from $34-37{ }^{\circ} \mathrm{C}$ to $15^{\circ} \mathrm{C}$ or $4{ }^{\circ} \mathrm{C}$ is very important to diminish the cold shock (Decuadro-

10 Hansen, 2004) and a general objective will be to evaluate the cooling procedure and

11 addition of glycerol to egg yolk (or specific substitutes, see below frozen semen chapter)

12 based extender. Also, the effects of adding antioxidants to the extender on viability and

13 fertility ability of spermatozoa will be analyzed. At present, the effects of different

14 combinations of extender, storage temperature and packaging on pregnancy rates after AI

15 with cooled/chilled stored semen could be analyzed.

17 3.2.- Frozen-thawed semen.

18 Sperm freezing in ram species is currently in a stagnant situation due to the scarce 19 diffusion of this process in its field of application. Various methods with commercial use 20 and acceptable results have been developed (Anel et al., 2003; Maxwell et al., 1995; Moses 21 et al., 1997) but their general application is restricted to intrauterine sperm deposition by 22 laparoscopy, because of the low fertility rates observed with thawed semen by vaginal23 cervical insemination (Curry, 2000), especially in induced oestrus. Nevertheless, freezing 24 methods can be improved, overall those related to handling of sperm, freezeability of the 25 cells and the increase of sperm populations recovered after cryopreservation. 
1 Low fertility rates of cryopreserved ram sperm are due to ultrastructural, biochemical and

2 functional changes undergone by a large sperm population, which leads to insufficient

3 movement and loss of viability of these spermatozoa in the genital tract (Salamon and

4 Maxwell, 2000). Ultrastructural changes mainly affect sperm membranes because during

5 the frozen-thawed process there is a redistribution of lipids that alters lipid-lipid and lipid-

6 protein relations which are necessary for the normal function of sperm membranes (Parks

7 and Graham, 1992).

8 One of the main components of dilution freezing extenders in ram species is egg yolk

9 because of its properties as a stabilizer and protector of the sperm membrane during

10 cryopreservation. Nevertheless, egg yolk has certain disadvantages, such as difficulty of

11 use, great variability of composition and the risk of microbiological contamination

12 (Bousseau et al.,. 1998). As a result, many studies have been carried out, mainly in bovine

13 species, on replacing egg yolk with its by-products or non-animal substances (Aires et al.,

14 2003). A good choice could be the use of pasteurized egg yolk (van Wagtendonk-de

15 Leeuw et al., 1999, bull sperm) or the use of powdered egg yolk (Marco-Jiménez et al.,

16 2004, ram sperm). Both studies reported similar results comparing with the use of

17 untreated egg yolk.

18 The active fraction of egg yolk is a low density lipoprotein (LDL) (Watson et al., 1975) but

19 the actual mechanism has not yet been elucidated. It has been suggested that egg yolk LDL

20 may stick on cellular membranes during the freezing-thawing process, avoiding the loss of

21 membrane phospholipids and increasing the tolerance to cryopreservation process (Graham

22 and Foote, 1987). Nevertheless, the role of protein and lipid components of LDL in these

23 interactions with the sperm membrane is still unknown. Some authors (Moussa et al., 2002;

24 Amirat et al., 2004) obtained good results using LDL in bull sperm. Other substances such

25 as phosphocaseinate or beta-lactoglobulin (Batellier et al., 1997 in ovine; Leboeuf et al., 
12003 in caprine) have been tested in refrigerated sperm but their utility in cryopreserved

2 semen has not been demostrated.

3 The use of alternative substances (pasteurized egg yolk, etc) allows standardized protocols

4 and reduces the risk of microbiological contamination. However, a better choice could be

5 the use of non-animal derived compounds. The most interesting of them may be soya

6 lecitine, which has a high content in egg yolk-like phospholipids. Other advantages, apart

7 from its vegetal origin, are its easy handling and standardization. Some authors (Aires et

8 al., 2003; Gil et al., 2003b; van Wagtendonk-de Leeuw et al., 2000) have tested soya

9 lecitine in cryopreserved extenders, obtaining contradictory results, making further studies

10 necessary. Currently, some commercial extenders, mostly used for bull sperm, include

11 soya derivates in their formulation.

12 In ovine species, glycerol is the main cryoprotectant used. Sperm survival is highly

13 affected by glycerol handling during the cryopreservation process (Anel et al., 2003). Thus,

14 the addition of glycerol in two steps at different temperatures seems to represent the best

15 balance between cytotoxicity and cryoprotection. Nevertheless, the variability of results

16 (Anel et al., 2003; Gil et al., 2003a; Salamon and Maxwell, 1995) leads to the conclusion

17 that more studies on the addition of glycerol and its relationship with dilution extenders

18 and freezing curves are required to obtain optimum AI results. Other substances (DMSO,

19 ethylene glycol, sugars, polymers, antifreeze fish proteins, etc) have been tested but they

20 seem to be inferior in comparison with results obtained using glycerol (Salamon and

21 Maxwell, 2000).

22 Also, other compounds, complementary to cryoprotective agents, can be used in order to

23 improve freezing-thawing results in ram sperm. For example, threalose improves fertility

24 rates in thawed semen applied by cervical insemination. This protective action may be due

25 to its antioxidant effects (Aisen et al., 2005). In addition, some seminal plasma proteins 
1 have been tested because they seem to protect the sperm membrane against cold shock and

2 this protection could be related to a decapacitating activity (Barrios et al., 2005). With regard to the cryopreservation process, a capital objective is the achievement

4 of the optimum cooling rate. In ram, Byrne et al. (2000) observed good fertility results with 5 rapid cooling rates $\left(-5^{\circ} \mathrm{C} / \mathrm{min}\right)$ both in vivo and in vitro. This was also observed by Kumar 6 et al (2003), who consider optimum cooling rates between -20 and $-30^{\circ} \mathrm{C} / \mathrm{min}$. Generally, 7 in the frozen-thawed process, membrane damage is produced if the freezing rate is between $8-15^{\circ} \mathrm{C}$ to $-60^{\circ} \mathrm{C}$ and, in ram sperm, the majority of damages occur from $-10^{\circ} \mathrm{C}$ to $-25^{\circ} \mathrm{C}$ 9 (Salamon and Maxwell, 1995). A significant improvement could be achieved with the use 10 of multithermic gradients (Arav et al., 2002). This allows to a continuous and progressive 11 adjustment of cooling and ice forming crystals which significantly reduces cryodamages.

12 The development of techniques which allow the use of thawed semen by vaginal-cervical 13 insemination would lead to important changes such as an increase in the number of 14 spermatozoa per dose. It is important because high sperm concentrations require special 15 adaptations of the cryopreservation process (Gil et al., 2002).

16 An interesting way of improving cryopreservation is the study of sperm subpopulations 17 which allows to select sexed or improved sperm. Ollero et al., (1998) demonstrated that the 18 initial heterogeneity of ejaculates is reduced by the freezing process. Therefore, it would be 19 interesting to study the special traits of cryopreservation methods applied to sexed sperm 20 or to some sperm subpopulations that could be of commercial interest (Suh et al., 2005; 21 Hollinshead et al., 2003; Mocé et al., 2006).

\section{4.- Artificial insemination procedures.}

24 The ideal technique for $\mathrm{AI}$ in any species is the intrauterine deposition of sperm 25 (intrauterine transcervical insemination). Indeed, this technique renders higher fertility 
1 results than when semen is placed in the vagina or the distal region of the cervix (King et

2 al., 2004; Paulenz et al., 2005). Deep levels of penetration in uterus in ewes (synchronized

3 oestrus) are necessary to obtain acceptable conception rates with cryopreserved semen.

4 Laparoscopy yields good results, since it places the seminal dose within the uterine horns,

5 but it is less practical that the transcervical AI. The anatomical structure of the ovine cervix

6 effectively prevents intrauterine deposition of semen with routine methods, based on the

7 use of straight catheters. The cervix is a highly complex fibrous structure, with many folds

8 obliterating the lumen from the vagina to the uterus, which adopts a sinuous form (Halbert

9 et al., 1990a; Kershaw et al., 2005). The cervical folds - from 3 to 7 - are of conical

10 shape (Halbert et al., 1990a; Kaabi, 2002), define a narrow lumen (1-3 mm of diameter)

11 and are misaligned being the lumen of the second fold generally eccentric (Halbert et al.,

12 1990a; Alvarez, 2000). Cervical folds can be classified in two morphological types: ring

13 and flap, the former being more frequent in young ewes (less than 2 years old). Flap-like

14 folds are penetrated more easily in AI (Kaabi et al., 2006).

15 The complexity of the ovine cervix affects AI catheter penetration. In fact, some cervical

16 variables are related to AI penetration: cervix length, external width (Alvarez, 2000), fold

17 number (Halbert et al., 1990a), eccentricity of the lumen of the folds (Alvarez, 2000), fold

18 type (Kaabi, 2002), distance between the external uterine orifice and the eccentric fold

19 (Halbert et al., 1990a; Kaabi, 2002). The cervical lumen has been studied using classical

20 morphometric techniques (Halbert et al., 1990a), indirect studies with silicon moulds

21 (Naqvi et al., 2005), tridimensional reconstruction from histological preparations or

22 nuclear magnetic resonance (NMR) (Alvarez, 2000). In the last study, the author reported

23 that there is great between-ewe variability, being the cause of difficulties encountered in

24 designing a standard AI catheter for this species. In fact, the lowest diameter of the cervix 
1 lumen was found in the eccentric fold, with only $1 \mathrm{~mm}(3 \mathrm{~mm}$ for Halbert et al., 1990c),

2 which is an important barrier for AI with conventional catheters (Figure 1).

3 The variations in the fertility achieved by AI in different ovine breeds (Donovan et al.,

4 2004) may be related to differences in the morphometric characteristics of the cervix

5 (Eppleston et al., 1994). Indeed, Kaabi el al. (2006) carried out a morphometric study in

6 four ovine breeds (Assaf, Churra, Castellana and Merino), showing important differences

7 on regard to length, width, number of folds and distance between folds (Table 2), which

8 originates breed variations in the depth of catheter penetration into the cervix. Thus, the

9 breeds yielding lower fertility after AI (Assaf and Churra) resulted in higher cervical

10 complexity, which hampered the insertion of the AI catheter, achieving a lesser degree of

11 cervical penetration.

12 All these morphological characteristics prevent the efficient penetration of conventional AI

13 catheters through the cervix to the uterus. The design of new catheters allowing 14 transcervical AI in ewes must take into account these findings, and benefit from them.

16 4.1.- Vaginal or intracervical deposition.

17 Vaginal or intracervical insemination is the most used AI technique in sheep. It renders acceptable results when using fresh or cooled $\left(15^{\circ} \mathrm{C}\right)$ semen, but it has several drawbacks, since it depends on short-term storage and on high spermatozoa per dose (lowering the

20 efficiency of the ram). Catheters are similar to those used in cattle but smaller, not 21 allowing deep insemination to be performed.

22 It has been showed that placing the dose inside the cervix increases fertility in comparison 23 with vaginal deposition (Kerton et al., 1984: 53\% vs. 31\%; Alvarez et al., 1998: 45\% vs $2422 \%$ ). Some authors have indicated that increasing insemination depth, restricted to the 25 distal part of the cervix, improves fertility results (Halbert et al., 1990c; Windsor et al., 
1 1994; Eppleston et al. 1994), provided that the cervix is not injured. Besides, Álvarez

2 (2000), studying the insemination depth with a straight catheter and the reflux of semen

3 back to the vagina, found an increase in fertility from vaginal deposition (type 0 ) to $2 \mathrm{~cm}$

4 depth (distal part of the cervix). Moreover, semen reflux also decreased with insemination

5 depth (Table 3 and Figure 2).

6 Many factors can affect the fertility of vaginal AI (Windsor, 1995, Anel et al., 2005). The

7 most important are: the type of semen (fresh, cooled or frozen), type of oestrus (natural or

8 induced) and insemination depth (Eppleston et al., 1994). The low fertility obtained when

9 using frozen-thawed semen in vaginal $\mathrm{AI}$ is due to the detrimental effect of

10 cryopreservation on spermatozoa, which reduces sperm transport, viability and fertility,

11 and increases embryo mortality (Salamon and Maxwell, 1995). Thus, fertility is low,

12 reporting 10-40\% (Maxwell and Hewitt, 1986; King et al., 2004); exceptionally, several

13 authors have reported high fertility result after inseminating ewes with natural oestrous

14 (Olesen et al., 1993: 58\%; Paulenz et al., 2005: 72\%). It is surprising that, considering the

15 advantages of using cryopreserved semen and the encouraging results found in several

16 published articles, there are currently no commercial programs applying cryopreserved

17 semen for intracervical AI, all of them resorting to AI by laparoscopy.

19 4.2.- Intrauterine deposition.

20 Ovine insemination by laparoscopy (Killen and Caffery, 1982) is the only methodology 21 that ensures intrauterine application of semen without reduction in fertility rates. Thawed 22 semen is always applied by laparoscopy in all AI commercial programs in ram. 23 Laparoscopy has multiple advantages such as high fertility results: $50-80 \%$ pregnant ewes 24 (Anel et al., 2003; Gourley et al., 1990; Maxwell et al., 1983), low number of spermatozoa 25 per dose, 20-50x $10^{6}$ spzs/dose, compared with cervical insemination (Davis et al., 1984; 
1 Maxwell, 1986), wide time margin for insemination compared with cervical insemination,

2 48/72h after sponge removal (Anel et al., 1992; Maxwell, 1986) and less dependence on

3 extrinsic factors with regard to cervical insemination (Anel et al., 2005).

4 Moreover laparoscopy allows ovary observation (Figure 3), thus the insemination of the

5 ipsilateral ovary is facilitated (fewer spermatozoa are needed). Laparoscopy can also be

6 simultaneously used to diagnose the reproductive tract, thus allowing those ewes with

7 reproductive problems (underdeveloped or malformed genitalia; ovarian or uterine

8 adhesions, ovarian pathologies, lack of response to oestrus induction, early gestations, etc)

9 to be removed from the insemination lot. These problems would go unnoticed when

10 performing vaginal-cervical insemination consequently impairing fertility results (Anel et

11 al., 2005).

12 At field level, laparoscopy AI have some problems related to its complexity, high cost (in

13 comparison with animal value), the need for trained technicians and other problems related

14 to animal welfare. Thus, laparoscopy has transitory use until problems related to the

15 transcervical approach are solved.

16 The incorporation of new technologies in assisted reproduction in ram species is a reduced

17 field but more adequate for laparoscopy insemination. Thus, poor quality sperm samples

18 (from high genetic value animals), epididymal sperm (Kaabi et al., 2003; Garcia-Macias et

19 al., 2005) or any problematic semen dose could be applied with high fertility guaranties

20 when deep intrauterine or oviductal sperm deposition are used (Jabbour et al., 1991). Also,

21 the use of sexed semen could be included in this methodology because sorting and

22 processing these samples affects sperm freezability (labile sperm populations). The low

23 performance and low number of recovered spermatozoa of semen sorting justify the use of

24 laparoscopy insemination in order to improve the profitability with good fertility results 
1 (Evans et al., 2004). Moreover, laparoscopy IA increased efficiency in the production of

2 suitable ovine zygotes in IVF programs (Ehling et al., 2003).

3 Intrauterine sperm deposition by transcervical method would be the ideal methodology for

4 ram AI. In spite of the number of experiments that have been carried out, there is currently

5 no protocol with acceptable fertility rates. The aim of this methodology is to reach uterus

6 without cervix traumas in a minimum amount of time. There are several methods for

7 crossing the cervix in ewe:

8 -Physical methods: attaching a haemostatic forceps to the external cervical os and

9 retracting the cervix to align the cervical os with the opening of the rings and decrease

10 obstructions to the uterine lumen (method by Andersen et al., 1973; method by Guelph,

11 Halbert et al., 1990b and 1990c). These methods are traumatic (Campbell et al., 1996) and

12 their commercial use is limited.

13 -Chemical methods: dilating the cervix with different hormones (oxytocin, $\mathrm{PGE}_{2}$ ). The 14 value of oxytocin as cervical dilator and its effect on fertility are controversial.

15 Pharmacological doses of oxytocin have been shown to relax the cervix and improve 16 cervical penetration but cervical traumas are still evident (Khalifa et al., 1992; Sayre and 17 Lewis, 1997). Stellflug et al., (2001) observed a negative effect in fertility per se. Kaabi 18 (2002) did not find an increase in cervical penetration when 200 IU of oxytocin were 19 injected and also showed a reduction in fertility results (38.24\% for the control group and $2016.92 \%$ for the oxytocin group respectively). King et al. (2004) concluded that oxytocin 21 administration as a cervical dilator cause a decrease in lambing rates (42\% vs. $10 \%$, control 22 group vs. oxytocin group).

23 -Mechanical methods: due to the difficulty in crossing the cervix by physical or hormonal 24 methods, the design of equipment which adapts to the anatomy of the cervix could be the 25 best way of achieving transcervical AI (Wulster-Radcliffe and Lewis, 2002). 
1 Several transcervical AI catheters have been used for passage through the cervix: pipette 2 with eccentric tip (Buckrell et al., 1992; Halbert et al., 1990b), pipette with bent tip

3 (Buckrell et al., 1994; Kaabi et al., 2000; Naqvi et al., 1998), helicoidal pipette (Eppleston

4 et al., 1994), semiflexible catheter (Wulster-Radcliffe et al., 2002), etc.

5 Based on previous reports on the minimum diameter of cervical lumen $(1 \mathrm{~mm})$ and the 6 high individual variation, Kaabi (2002) designed various catheters for transcervical AI 7 (Figure 4). Three major characteristics of these catheters are: minimum diameter, eccentric 8 tip (which allows the passage through eccentric rings), and rigidity (more effective in 9 progression but also more traumatic in comparison with flexible catheters). Modified 10 catheters achieve uterus in a high proportion of attemps (60-85\%) but fertility results are 11 lower (from 10 to $40 \%$ ) when compared with uterine deposition by laparoscopy (50-70\%) 12 (Buckrell et al., 1993; Windsor et al., 1994, Wulster-Radcliffe et al., 2004). Kaabi (2002) 13 observed that this fertility reduction is related to zone and penetration degree in the cervix. 14 Fertility increased significantly up to $3 \mathrm{~cm}$ in depth, but deeper cervical inseminations or 15 transcervical intrauterine result in a decreased fertility rates (Table 4).

16 In order to explain this decrease in fertility, Kaabi (2002) carried out cervical 17 manipulations (identical to those performed in transcervical insemination) during 18 intrauterine insemination by laparoscopy. As we can see in Table 5, deep cervical 19 manipulations reduced fertility rates.

20 In this sense, Wulster-Radcliffe et al., (2002 and 2004) obtained inferior fertility results 21 with a semiflexible catheter in transcervical insemination (4.0\%) in comparison with 22 laparoscopy insemination $(41.0 \%)$. Their hypothesis is that cervical manipulations 23 associated with catheter could activate pathways that interrupt pregnancy between days 3 24 and 14. In conclusion, they checked the elimination of any visual evidence of trauma and 
1 they also observed that the procedure does not seem to affect sperm transport or embryo

2 survival until day 3.

3 Transcervical insemination with catheters could induce subtle damages in sensitive zones

4 of the cervix (delayed effects in embryonic implantation), and also unleash hormonal

5 imbalance in postovulatory period (Raynal and Hodeau, 2004). These authors showed an

6 increase in oxytocin as response to adrenergic stimuli (induced by vaginal speculum) and

7 this increase could be related to reduced fertility.

8 Summarizing, mechanical aspects of transcervical AI seem to be solved but the fertility

9 results for this methodology are still reduced. Further studies are necessary for the

10 improvement of this technique.

11 5.- Assessment of ram sperm.

12 Fertility is a high complex biological function which depends on various cellular properties

13 such as spermatozoa movement, recognition signals among cells, cell membrane

14 properties, chromatin status, etc. Therefore, fertility assessment must be a compound

15 process including evaluation of different traits of sperm function.

16 In the case of ram, due to specific problems in AI, the development of sperm assessment

17 techniques predictive to field fertility constitutes an important aim in the progress of

18 assisted reproduction. It has been demonstrated that conventional techniques are not able to

19 accurately and repeatedly estimate the fertility of a semen sample (Correa et al., 1997). The

20 development of techniques that pursue to evaluate the functional status of sperm organelles

21 (acrosomes, mitochondria) or the integrity of many cellular components (membranes,

22 chromatin) have been gaining importance during the last decades (Martinez-Pastor et al.,

23 2004). Furthermore, the development of these techniques would enable the accurate daily

24 evaluation of sperm batches. Besides, they could be used for the evaluation and

25 enhancement of preservation protocols. The use of techniques with a high predictive value 
1 for fertility would result in improvements in AI, offering the possibility of intravaginal

2 deposition when applying thawed semen.

3 Sperm fertility traits can be classified into compensable -meaning that the deficiency can

4 be removed by increasing sperm dose- and uncompensable- when the deficiency cannot be

5 eliminated by increasing sperm dose alone. Although the compensable aspects of semen

6 quality address the ability of inseminated sperm to access the oocyte, the uncompensable

7 aspects address the quality or competence of the fertilizing sperm to continue or sustain the

8 fertilization process and hence the resulting embryo (Evenson, 1999). It would be

9 interesting to detect those rams without compensable sperm defects because the result

10 would be high availability of sperm doses in these males.

\section{$11 \quad$ 5.1.- Basic techniques.}

12 Currently, sperm assessment in AI centres is based on conventional techniques such as 13 external aspect (volume and colour), subjective motility (wave move and individual 14 motility) and sperm concentration (mainly using a spectrophotometer). These are practical 15 and fast assays and require simple equipment that effectively detects semen samples of 16 poor quality. These assessments could be enough when cervical insemination is applied 17 because there is a high number of spermatozoa per dose, so it makes up for compensable 18 defects. Nevertheless, better estimation of sperm quality is required when thawed semen is 19 used. Furthermore, in specific situations (subfertility problems, accurate sperm evaluation 20 of males, etc) these techniques are insufficient due to their high subjectivity, low 21 sensitivity and poor correlation with field fertility. Also, these assays are based on the 22 detection of compensable traits and do not include uncompensable ones.

\section{$23 \quad$ 5.2.- New trends in sperm assessment.}

24 These assays have many advantages such as high sensitivity, automation and objectivity 25 and some of them are well-correlated with field fertility. One of their drawbacks is the 
1 complex and expensive equipment that usually required. We have summarized a brief

2 description of some of the most important techniques bellow:

3 Sperm motility automated assessment. Motility is commonly believed to be one of the

4 most important characteristics associated with the fertilizing ability of sperm. It is an

5 expression of viability and structural integrity of the spermatozoon. The assessment of

6 subjective motility has a reduced fertility predictive value due to the high variability

7 observed between individuals. Thus, variations of 30 to $60 \%$ have been reported in the

8 estimation of motility in the same ejaculate. Because of this, emphasis has been placed on

9 the development of objective methods to assess semen motility parameters. Some studies

10 carried out in humans and rats showed that velocity parameters have good correlation with

11 fertility in vitro or in vivo results (Verstegen et al., 2002).

12 The accuracy and precision of CASA systems have allowed to the detection of subtle

13 changes in sperm motion and therefore, improved discrimination among treatments in

14 laboratory studies of new extenders, cryoprotectants and other processes (Amann and Katz,

15 2004).

16 Besides, this technique has allowed to distinguish different sperm subpopulation within

17 sperm samples (Martinez-Pastor et al., 2005b; Martinez-Pastor et al., 2005c). The study of

18 subpopulations has recently been considered as an important tool, and many authors have

19 found that susceptibility to capacitation and fertilizing ability varies depending on the

20 subpopulation studied (Harrison, 1996; Olds-Clarke and Sego, 1992; Williams and Ford, $212001)$.

22 Kinematic aspects of ram spermatozoa were defined by Mortimer and Maxwell, 1999.

23 More recently other authors have used this automated process in this species (Marco-

24 Jimenez et al., 2005; Martinez-Pastor et al., 2004). Nowadays, some insemination centres

25 are adopting CASA analysis in their routine for sperm assessment but, generally, only as 
1 standardized method to calculate total and progressive motility. Therefore, velocity

2 parameters, which are the most correlated with fertility, are not used and the evaluation of

3 sperm subpopulations in ram has not been applied yet.

4 Membrane status and sperm viability. The assessment of subtle membrane damage and

5 sperm viability is important because semen processing methods, such as freezing and

6 thawing, results in the death of large numbers of spermatozoa. Due to the need for a certain

7 population of motile, viable, non-capacitated spermatozoa with intact acrosomes in the

8 frozen-thawed AI dose, it is crucial that these sperm parameters be tested (Kavak et al.,

9 2003). Many different probes have been developed in order to assess plasma membrane

10 integrity and acrosome status, frequently using fluorescent markers. Further advantages are

11 obtained when flow cytometry is used, by assessing larger populations of cells. In ram,

12 fluorescence microscopy has been applied to assess sperm viability using

13 carboxyfluorescein diacetate and propidium iodide (CFDA/PI) (Grasa et al., 2004; Yaniz et

14 al., 2005). Other authors used the double stain SYBR-14/PI with fluorescence microscopy

15 (Diaz et al., 2002; Gil et al., 2003a; Gil et al., 2003b; Gil et al., 2002; Paulenz et al., 2002)

16 in this species. Nevertheless, although these stains discriminate between dead and live cells

17 (and also moribund ones in the case of SYBR-14/PI, Figure 5, a), but it is necessary to

18 detect subtle damages in the sperm membrane that could affect sperm functionality.

19 Asymmetry of the membrane phospholipids occurs during the early phases of disturbed

20 membrane function, before the integrity of the plasma membrane is progressively damaged

21 (Martin et al., 1995). When the cell membrane is disturbed the phospholipid

22 phosphatidylserine is translocated from the inner to the outer leaflet of the plasma

23 membrane, thus this sign of early apoptosis can be monitored by the calcium-dependent

24 binding of Annexin-V. In human, bull and boar Annexin V (labelled with FITC stain)

25 combined with PI appears to be suitable for early subtle membrane damage (Pena et al., 
1 2003). In ram, the information on subtle membrane damage is scarce. Garcia-Macias et al.

2 (2003) compared bull and ram results using Annexin V-FITC with PI. Muller et al., (1999)

3 studied the transbilayer distribution of phospholipids after cryopreservation and concluded

4 that the cryopreservation process does not affect this distribution in intact (PI negative)

5 cells.

6 Another important point related to membrane integrity is the evaluation of acrosomal

7 status. In ram several fluorescent probes have been used for this purpose (Paz et al., 2002;

8 Martinez-Pastor et al., 2005a; Valcarcel et al., 1997). One of the most commonly used is

9 the double stain PNA-FITC/PI (Figure 5, b).

$10 \underline{\text { Mitochondrial status }}$ has an important role in sperm functionality because of its

11 relationship with the energetic status of the cell and sperm motility, and because it has also

12 been related to fertility (Casey et al., 1993; Kasai et al., 2002). There is an evidence that

13 mitochondrial injury during freezing is involved in the poor fertility of frozen semen used

14 for cervical insemination (Windsor, 1997). Thus, it would be an important assay to develop

15 in this species. Various fluorochromes have been used for its evaluation. Rhodamine

16 123/PI has been applied in ram sperm, using fluorescence microscopy (Grasa et al., 2004;

17 Windsor, 1997; Windsor and White, 1993). JC-1 is a fluorescent dye that has been

18 successfully used with both fluorescence microscopy and flow cytometry (Diaz et al.,

19 2003; Garner et al., 1997; Gravance et al., 2000; Thomas et al., 1998). In ram sperm, JC-1

20 results have been correlated with sperm motility in frozen-thawed sperm (Martinez-Pastor

21 et al., 2004).

22 Capacitation status of ram spermatozoa has been evaluated using chlortetracycline (CTC)

23 (Gil et al., 2002; Gil et al., 2000; Mortimer and Maxwell, 1999; Paulenz et al., 2002). But

24 this staining must be used with fluorescence microscopy so it is slow and subjective.

25 Furthermore, it only evaluates the later stages of capacitation ( $\mathrm{Ca} 2+$ mediated changes) 
1 (Kavak et al., 2003). There are other stainings which can be used with flow cytometry,

2 such as the membrane fluidity marker Merocyanine 540 (Marco-Jimenez et al., 2005).

3 Morphology and morphometry. Normal sperm morphology may be an indicator of the

4 fertility potential, but subjective methods of assessment have shown considerable between-

5 technician and between-laboratory variation. The development of computer-assisted

6 spermatozoa (CASMA: computer assisted sperm morphometry analysis) has allowed to

7 reduce the components of variation in the evaluation of sperm morphology and to reveal

8 subtle differences between individuals which cannot be detected using subjective methods

9 (Figure 5, c). It is noteworthy that spermatozoa head shape may be related to sperm

10 chromatin organization. Therefore, potential problems in DNA may result in subtle

11 changes in sperm head shape that could be detectable with CASMA. Besides, sperm

12 subpopulation can be defined according to the morphometry of sperm heads, and the

13 distribution of these subpopulations may be related to the fertility of the sample.

14 CASMA has allowed to detect morphometric differences in sperm head dimensions

15 between fertile and subfertile males in some species such as stallion (Casey et al., 1997). In

16 ram, some studies have been carried out to develop accurate methods for employing

17 CASMA of ram sperm heads (Gravance et al., 1998; Sancho et al., 1998), and others have

18 analyzed the effect of cryopreservation in sperm heads (Lambrechts et al., 2000). The

19 possible relationship between CASMA and fertility is still to be proved in this species.

20 Chromatin status. The nucleus is considered as the strongest indicator of semen quality and

21 its assessment should be a priority in the spermiogram. With this aim, many fluorochrome-

22 based techniques have been developed. The SCSA (sperm chromatin structure assay) is

23 one of the most used ones in the last two decades because it combines the properties of

24 acridine orange with flow cytometry which allows to analyze high numbers of cells in little

25 time. This technique defines abnormal chromatin structure as an increased susceptibility of 
1 sperm DNA to acid-induced denaturation in situ. Increased susceptibility to denaturation

2 corresponds to heterogeneity in the chromatin structure, which is associated with

3 disturbances during spermatogenesis or to subsequent chromatin damage, and which leads

4 to reduced fertility (Ballachey et al., 1987; Evenson et al., 2002). Some correlations have

5 been obtained between sperm motility, viability and capacitation status with SCSA

6 parameters in ram (Peris et al., 2004). These authors also observed that SCSA parameters

7 were higher because of cryopreservation, after incubating post-thawed spermatozoa for 20

8 hours in synthetic oviductal fluid. Other authors have obtained a good relationship between

9 SCSA parameters and individual male variation (Martinez-Pastor et al., 2004). Also, a

10 negatively correlation has been observed in ram between DNA fragmentation index

11 calculated by SCSA and progressive motility and percentage of morphologically normal

12 spermatozoa, and a positive correlation with the percentage of primary sperm defects

13 (Kasimanickam et al., 2006). Recently, SCSA has been applied in ram to compare the

14 chromatin status of samples obtained from caput, corpus and cauda epididymides, and

15 ejaculated sperm (Garcia-Macias et al., 2006). In other species (human, boar and bull)

16 there are studies in which fertility has been correlated with chromatin status detected by

17 SCSA (Evenson and Wixon, 2006) but there is a lack of information on such a relationship

18 in ram.

19 Reactive Oxygen Species (ROS). Excess production of ROS or a decreased level of 20 antioxidant enzymes affect sperm motility and viability and cause sperm defects by 21 initiating an oxidation chain reaction damaging proteins lipids and DNA (Aitken and 22 Baker, 2004; Sikka, 2004). The sperm oxidative enzymes that help counteract the effects of 23 ROS activity include superoxide dismutase (SOD), catalase, glutathione peroxidase (GPx), 24 and glutathione reductase (Sikka, 2004). The quantification of these enzymes both on 25 spermatozoa and seminal plasma, and the evaluation of ROS effects in proteins, lipids and 
1 DNA it would be of great interest when there are subfertility problems are present or when

2 different preservation protocols are being tested. In ram, the adverse effects of ROS on

3 spermatozoa are more likely to be caused by direct oxidation of proteins and membrane

4 permeabilisation than by disturbance of lipid fluidity (Christova et al., 2004).

5 Kasimanickam et al. (2006) obtained a negative correlation in ram spermatozoa between

6 classical semen parameters and lipid peroxidation and GPx activity. They also observed

7 lower lipid peroxidation and GPx activity in both seminal plasma and spermatozoa in the

8 groups of samples that they classified as satisfactory and questionable, but the SOD was

9 lower in the unsatisfactory group. Thus, there are indications that SOD and GPx have

10 crucial protective roles against the toxic effect of ROS in ram-lamb semen and

11 consequently this research line must be deeply explored.

12 In vitro fertility analysis. IVF of homologous oocytes is one of the most informative

13 methods for assessing sperm fertilizing ability in vitro. Recently, O'meara et al., 2005

14 observed significant differences between high and low fertility rams regarding to the

15 percentage of oocytes cleaved obtaining a correlation between fertility in vivo and cleavage

16 rate in vitro. They suggested that it would be a useful method for predicting field fertility

17 of frozen-thawed ram semen. Nevertheless, it is a laborious and complex assay (high cost 18 and high statistical complexity, etc).

20 6.- References.

21 Aires VA, Hinsch KD, Mueller-Schloesser F, Bogner K, Mueller-Schloesser S, Hinsch E,

22 2003: In vitro and in vivo comparison of egg yolk-based and soybean lecithin-based

23 extenders for cryopreservation of bovine semen. Theriogenology 60 269-279.

24 Aisen EG, Medina VH, Venturino A, 2002: Cryopreservation and post-thawed fertility of

25 ram semen frozen in different trehalose concentrations. Theriogenology 57 1801-1808. 
1 Aisen EG, Quintana M, Medina VH, Morello H, Venturino A, 2005: Ultramicroscopic and

2 biochemical changes in ram spermatozoa cryopreserved with trehalose-based hypertonic

3 extenders. Cryobiology 50 239-249.

4 Aitken RJ, Baker MA, 2004: Oxidative stress and male reproductive biology. Reprod.

$5 \quad$ Fertil. Dev. 16 581-588.

6 Álvarez M, 2000: Estudio del cuello uterino en la oveja Churra como método de mejora de

7 la vía vaginal en la inseminación artificial. Thesis Doctoral. Veterinary School, University

8 of León, Spain.

9 Álvarez M, Anel L, Anel E, Boixo JC, Paz P, Chamorro C, Peña FJ, Domínguez JC,

10 Celorrio I, 1998: Relation between the depth of cervical insemination and prolificacy in

11 sheep. In proc: 50th ICAR: Gametes. Development and Function. Milan, Italy 504.

12 Amann RP, Katz DF, 2004: Reflections on CASA after 25 years. J Androl 25 317-325.

13 Amirat L, Tainturier D, Jeanneau L, Thorin C, Gerard O, Courtens JL, Anton M, 2004:

14 Bull semen in vitro fertility after cryopreservation using egg yolk LDL: a comparison with

15 Optidyl, a commercial egg yolk extender. Theriogenology 61 895-907.

16 Andersen K, Aamdal J, Fougner JA, 1973: Intrauterine and deep cervical insemination

17 with frozen semen in sheep. Zuchthyg. 8 113-118.

18 Anel L, Boixo JC, Anel E, Carbajo M, Domínguez JC, Olmedo JA, Melcon C. 1992:

19 Fertility of Churra Ewes following intrauterine insemination by laparoscopy with frozen-

20 thawed semen In proc: 12th Int. Cong. on Anim. Reprod.\& AI. The Hage, Holland 1384211386.

22 Anel L, Kaabi M, Abroug B, Alvarez M, Anel E, Boixo JC, de la Fuente LF y Paz P, 2005:

23 Factors influencing the fertility of vaginal and laparoscopic artificial insemination in 24 churra ewes: a field assay. Theriogenology 63 1235-1247. 
1 Anel L, de Paz P, Alvarez M, Chamorro CA, Boixo JC, Manso A, Gonzalez M, Kaabi M,

2 Anel E, 2003: Field and in vitro assay of three methods for freezing ram semen.

3 Theriogenology 60 1293-1308.

4 Arav A, Zeron Y, Shturman H, Gacitua H, 2002: Successful pregnancies in cows

5 Ballachey BE, Hohenboken WD, Evenson DP, 1987: Heterogeneity of sperm nuclear

6 chromatin structure and its relationship to bull fertility. Biol. Reprod. 36 915-925.

7 Barrios B, Fernandez-Juan M, Muino-Blanco T, Cebrian-Perez JA, 2005:

8 Immunocytochemical localization and biochemical characterization of two seminal plasma

9 proteins that protect ram spermatozoa against cold shock. J.Androl. 26 539-549.

10 Batellier F, Magistrini M, Fauquant J, Palmer E, 1997: Effects of milk fractions on survival 11 of equine spermatozoa. Theriogenology 48 391-410.

12 Batellier F, Vidament M, Fauquant J, Duchamp G, Arnaud G, Yvon JM, Magistrini M, 13 2001: Advances in cooled semen techonology. Animal Reproduction Science 68 181-190.

14 Bousseau S, Brillard JP, Marguant-Le GB, Guerin B, Camus A, Lechat M, 1998:

15 Comparison of bacteriological qualities of various egg yolk sources and the in vitro and in 16 vivo fertilizing potential of bovine semen frozen in egg yolk or lecithin based diluents.

17 Theriogenology 50 699-706.

18 Buckrell BC, Buschbeck C, Gartley CJ, Croetsch T, McCutcheon W, Martín J, Penner

19 WK, Walton J. S. 1992: A breeding trial using a transcervical technique for artificial 20 insemination in sheep. In Proc 12th. Int. Cong. on Anim.Reprod.\& AI, The Hague 21 Holland. 3 1531-1533.

22 Buckrell BC, Buschbeck C, Gartley CJ, Croetsch T, McCutcheon W, Martin J, Penner

23 WK, Walton JS, 1994: Further development of a transcervical technique for artificial 24 insemination in sheep using previously frozen semen. Theriogenology 42 601-611. 
1 Buckrell BC, Gartley CJ, Buschbeck C, Jordan P, Walton JW, 1993: Evaluation of a

2 transcervical AI technique for transferring embryos in sheep. Theriogenology 39 197-197.

3 Byrne G P, Lonergan P, Wade M, Duffy P, Donovan A, Hanrahan JP, Boland MP, 2000:

4 Effect of freezing rate of ram spermatozoa on subsequent fertility in vivo and in vitro.

5 Anim. Reprod.Sci. 62 265-275.

6 Campbell JW, Harvey TG, McDonald MF, Sparksman RI, 1996: Transcervical

7 insemination in sheep: an anatomical and histological evaluation. Theriogenology $451535-$

81544.

9 Casey PJ, Gravance CG, Davis RO, Chabot DD, Liu IKM, 1997: Morphometric 10 differences in sperm head dimensions of fertile and subfertile stallions. Theriogenology 47 $11 \quad 575-582$.

12 Casey PJ, Hillman RB, Robertson KR, Yudin AI, Liu IK, Drobnis EZ, 1993: Validation of 13 an acrosomal stain for equine sperm that differentiates between living and dead sperm. J. 14 Androl. 14 289-297.

15 Christova Y, James PS, Jones R, 2004: Lipid diffusion in sperm plasma membranes 16 exposed to peroxidative injury from oxygen free radicals. Mol. Reprod. Dev. 68 365-372.

17 Correa JR, Pace MM, Zavos PM, 1997: Relationships among frozen-thawed sperm 18 characteristics assessed via the routine semen analysis, sperm functional tests and fertility 19 of bulls in an artificial insemination program. Theriogenology 48 721-731.

20 Curry MR, 2000: Cryopreservation of semen from domestic livestock. Rev.Reprod. 5 462152.

22 Davis IF, Kerton DJ, Mcphee SR, White MB, Banfield JC, Cahill LP, Grant I, 1984:

23 Uterine artificial insemination in ewes. In: Reprodution in sheep. Eds: Lindsay DR and 24 Pearce, DT, Cambridge Univ. Press., 304-305. 
1 Decuadro-Hansen G, 2004: Chilled and frozen semen: the animal experience. Gynecologie

2 Obstetrique \& Fertility 32 887-893.

3 Diaz AR, Martinez-Pastor F, Alvarez M, Anel L, Rodriguez C, Kaabi M and Paz P, 2003:

4 Assessment of mitochondrial activity in ram semen through staining with the fluorescent

5 probe JC-1. Theriogenology 59217.

6 Diaz AR, Martinez-Pastor F, Anel E, Alvarez M, Anel L, Boixo JC, Muro JD, Herraez P

7 and Paz P, 2002: Viability assessment of ovine sperm using dual staining SYBR-14-PI. In

8 proc. 9th International Symposium of Spermatology Cape Town, SA. P1.02.

9 Donovan A, Hanrahan JP, Kummen E, Duffy P, Boland MP, 2004: Fertility in the ewe 10 following cervical insemination with fresh or frozen-thawed at a natural or syncronized 11 oestrus. Anim. Reprod. Sci. 84 359-368.

12 Ehling C, Wirth P, Schindler L, Hadeler KG, Dopke HH, Lemme E, Herrmann, Niemann

$13 \mathrm{H}, 2003$ : Laparoscopical intrauterine insemination with different doses of fresh, conserved,

14 and frozen semen for the production of ovine zygotes. Theriogenology 60 777-787.

15 Eppleston J, Salamon S, Moore NW, Evans G, 1994: The depth of cervical insemination 16 and site of intrauterine insemination and their relationship to the fertility of frozen-thawed 17 ram semen. Anim. Reprod. Sci. 36 211-225.

18 Evans G, Hollinshead FK, Maxwell WM, 2004: Preservation and artificial insemination of 19 sexed semen in sheep. Reprod.Fertil.Dev 16 455-464.

20 Evenson DP, 1999 Loss of livestock breeding efficiency due to uncompensable sperm 21 nuclear defects. Reprod. Fertil. Dev. 11 1-15.

22 Evenson DP, Larson KL, Jost LK, 2002: Sperm chromatin structure assay: its clinical use 23 for detecting sperm DNA fragmentation in male infertility and comparisons with other 24 techniques. J. Androl. 23 25-43. 
1 Evenson DP, Wixon R, 2006: Clinical aspects of sperm DNA fragmentation detection and

2 male infertility. Theriogenology 65 979-991.

3 Fernandez-Abella D, Preve MO, Villegas N, 2003: Insemination time and dilution rate of

4 cooled and chilled semen affects fertility. Theriogenology 60 21-26.

5 Foote RH, Brockett CC, Kaproth MT, 2002: Motility and fertility bull sperm in whole milk

6 extender containing antioxidants. Anim. Reprod. Sci. 71 13-23.

7 Garcia-Macias V, Martinez-Pastor F, Alvarez M, Garde JJ, Anel E, Anel L, Paz P; 2006;

8 Assessment of chromatin status (SCSA®) in epididymal and ejaculated sperm in Iberian

9 red deer, ram and domestic dog. Theriogenology (in press).

10 Garcia-Macias V, Martinez-Pastor F, Alvarez M, Paz P, Anel E, Anel L, 2005: Ram

11 spermatozoa quality parameters are less affected by storage in the cauda epididymis than in

12 refrigeration media. Reprod. Dom. Anim. 40393.

13 Garcia-Macias V, Martinez-Pastor F, Paz P, Anel E, Alvarez M, Kaabi M, Muro JD, Anel

14 L, 2003: Annexin V-FITC/PI assay in bull and ram semen. Theriogenology 59220.

15 Garner DL, Thomas CA, Joerg HW, DeJarnette JM, Marshall CE, 1997: Fluorometric 16 assessments of mitochondrial function and viability in cryopreserved bovine spermatozoa.

17 Biol. Reprod. 57 1401-1406.

18 Gil J, Lundeheim N, Soderquist L, Rodriguez-Martinez H, 2003a: Influence of extender,

19 temperature, and addition of glycerol on post-thaw sperm parameters in ram semen.

20 Theriogenology 59 1241-1255.

21 Gil J, Rodriguez-Irazoqui M, Lundeheim N, Soderquist L, Rodriguez-Martinez H, 2003b:

22 Fertility of ram semen frozen in Bioexcell and used for cervical artificial insemination.

23 Theriogenology 59 1157-1170. 
1 Gil J, Rodriguez-Irazoqui M, Soderquist L, Rodriguez-Martinez H, 2002: Influence of

2 centrifugation or low extension rates prefreezing on the fertility of ram semen after

3 cervical insemination. Theriogenology 57 1781-1792.

4 Gil J, Soderquist L, Rodriguez-Martinez H, 2000: Influence of centrifugation and different

5 extenders on post-thaw sperm quality of ram semen. Theriogenology 54 93-108.

6 Gourley DD, Riese RL, 1990: Laparoscopic artificial insemination in sheep. Vet. Clin.

7 North. Am. Food. Anim. Pract. 6 615-633

8 Graham JK, Foote RH, 1987: Effect of several lipids, fatty acyl chain length, and degree of

9 unsaturation on the motility of bull spermatozoa after cold shock and freezing.

$10 \quad$ Cryobiology 24 42-52.

11 Grasa P, Perez-Pe R, Baguena O, Forcada F, Abecia A, Cebrian-Perez JA, Muino-Blanco

12 T, 2004: Ram sperm selection by a dextran/swim-up procedure increases fertilization rates

13 following intrauterine insemination in superovulated ewes. J. Androl. 25 982-990.

14 Gravance CG, Champion ZJ, Casey PJ, 1998: Computer-assisted sperm head morphometry

15 analysis (ASMA) of cryopreserved ram spermatozoa. Theriogenology 49 1219-1230.

16 Gravance CG, Garner DL, Baumber J, Ball BA, 2000: Assessment of equine sperm

17 mitochondrial function using JC-1. Theriogenology 53 1691-1703.

18 Halbert GW, Dobson H, Walton JS, Buckrell BC, 1990a: The structure of the cervical

19 canal of the ewe. Theriogenology 33 977-992.

20 Halbert GW, Dobson H, Walton JS, Buckrell BC, 1990b: A technique for transcervical 21 intrauterine insemination of ewes. Theriogenology 33 993-1010.

22 Halbert GW, Dobson H, Walton JS, Sharpe P, Buckrell BC, 1990c: Field evaluation of a 23 technique for transcervical intrauterine insemination of ewes. Theriogenology $331231-$ 1243. 
1 Harrison RA, 1996: Capacitation mechanisms, and the role of capacitation as seen in

2 eutherian mammals. Reprod. Fertil. Dev. 8 581-594.

3 Hollinshead FK, Gillan L, O'Brien JK, Evans G, Maxwell WM, 2003: In vitro and in vivo

4 assessment of functional capacity of flow cytometrically sorted ram spermatozoa after

5 freezing and thawing. Reprod.Fertil.Dev. 15 351-359.

6 Jabbour H N; Evans, G, 1991: Fertility of superovulated ewes following intrauterine or

7 oviducal insemination with fresh or frozen-thawed semen. Reprod. Fertil. Dev: 3 1-7.

8 Kaabi M, 2002: Análisis de factores morfoestructurales, instrumentales y metodológicos de

9 la inseminación transcervical en la oveja. Thesis Doctoral. Veterinary School, University 10 of León, Spain.

11 Kaabi M, Álvarez M, Anel E, Boixo JC, Chamorro CA; Olmedo JA, Martínez S, Anel L,

12 2000: Mechanical aspects of cervical penetration in sheep depending on pippete type. In

13 proc 14th Int. Congr. on Anim. Reprod. \& AI. Stockhom, Sweden 15:16.

14 Kaabi M, Alvarez M, Anel E, Chamorro CA, Boixo JC, de Paz P, Anel L, 2006: Influence

15 of breed and age on morphometry and depth of inseminating catheter penetration in the

16 ewe cervix: a postmorten study. Theriogenology (in press).

17 Kaabi M, Paz P, Álvarez M, Anel E, Boixo JC, Roussi, H, Herráez P, Anel L, 2003: Effect

18 of epididymis handling conditions on the quality of ram spermatozoa recovered post-

19 mortem.Theriogenology 60 1249-1259.

20 Kasai T, Ogawa K, Mizuno K, Nagai S, Uchida Y, Ohta S, Fujie M, Suzuki K, Hirata S,

21 Hoshi K, 2002: Relationship between sperm mitochondrial membrane potential, sperm

22 motility, and fertility potential. Asian J. Androl. 4 97-103.

23 Kasimanickam R, Pelzer KD, Kasimanickam V, Swecker WS, Thatcher CD, 2006:

24 Association of classical semen parameters, sperm DNA fragmentation index, lipid 
1 peroxidation and antioxidant enzymatic activity of semen in ram-lambs. Theriogenology

$2651407-1421$.

3 Kavak A, Johannisson A, Lundeheim N, Rodriguez-Martinez H, Aidnik M, Einarsson S,

4 2003: Evaluation of cryopreserved stallion semen from Tori and Estonian breeds using

$5 \quad$ CASA and flow cytometry. Anim. Reprod. Sci. 76 205-216.

6 Kershaw CM, Khalid M, McGowan MR, Ingram K, Leethongdee S, Wax G, Scaramuzzi

7 RJ, 2005: The anatomy of the sheep cervix and its influence on the transcervical passage of

8 an inseminating pipette into the uterine lumen. Theriogenology $641225-1235$

9 Kerton DJ, McPhee SR, Davis IF, White MB, Banfield JC, Cahill LP, 1984: A comparison

10 of insemination techniques in Corridale ewes. In Proc. Aust. Soc. Anim. Prod. 15701.

11 Khalifa RM, Sayre BL, Lewis GS, 1992: Exogenous oxytocin dilates the cervix in ewes.

12 J.Anim.Sci. 70 38-42.

13 Killeen ID, Caffery GJ, 1982: Uterine insemination of ewes with the aid of a laparoscope.

14 Austr Vet J 5995.

15 King ME, Mckelvey WAC, Dingwall WS, Matthews KP, Gebbie FE, Mylne MJA, Stewart

16 E, Robinson JJ, 2004: Lambing rates and litter sizes following intrauterine or cervical

17 insemination of frozen/thawed semen with $\mathrm{o}$ without oxytocin administration.

18 Theriogenology 62 1236-1244.

19 Kumar S, Millar JD, Watson PF, 2003: The effect of cooling rate on the survival of

20 cryopreserved bull, ram, and boar spermatozoa: a comparison of two controlled-rate

21 cooling machines. Cryobiology 46 246-253.

22 Lambrechts H, van Niekerk FE, Cloete SW, Coetzer WA, van der HG, 2000: Sperm

23 viability and morphology of two genetically diverse Merino lines. Reprod. Fertil. Dev. 12

$24 \quad 337-344$. 
1 Leboeuf B, Guillouet P, Batellier F, Bernelas D, Bonne JL, Forgerit Y, Renaud G,

2 Magistrini M, 2003: Effect of native phosphocaseinate on the in vitro preservation of fresh

3 semen. Theriogenology 60 867-877.

4 Lopez-Saez A, Ortiz N, Gallego L, Garde JJ, 2000: Liquids storage (5 degrees C) of ram

5 semen in different diluents. Arch. Androl. 44 155-164.

6 Marco-Jimenez F, Puchades S, Gadea J, Vicente JS, Viudes-de-Castro MP, 2005: Effect of

7 semen collection method on pre and post-thaw Guirra ram spermatozoa. Theriogenology $8 \quad 641756-1765$.

9 Marco-Jimenez F, Puchades S, Moce E, Viudes-de-Cartro MP, Vicente JS, Rodriguez M,

10 2004: Use of powdered egg yolk vs fresh egg yolk for the cryopreservation of ovine

11 semen. Reprod.Domest.Anim. 39 438-441.

12 Martin SJ, Reutelingsperger CP, McGahon AJ, Rader JA, van Schie RC, La Face DM, 13 Green DR, 1995: Early redistribution of plasma membrane phosphatidylserine is a general 14 feature of apoptosis regardless of the initiating stimulus: inhibition by overexpression of 15 Bcl-2 and Abl. J. Exp. Med. 182 1545-1556.

16 Martinez-Pastor F, Castro D, Bernardo J, Iglesias M, Herraez P, Paz P, Anel L, 2005a:

17 Comparison of several acrosomal probes on ram spermatozoa. Reprod. Dom. Anim. 40 $18 \quad 392-393$.

19 Martinez-Pastor F, Diaz-Corujo AR, Anel E, Herraez P, Anel L, Paz P, 2005b: Post 20 mortem time and season alter subpopulation characteristics of Iberian red deer epididymal 21 sperm. Theriogenology 64 958-974.

22 Martinez-Pastor F, Garcia-Macias V, Alvarez M, Herraez P, Anel L, de Paz P, 2005c: 23 Sperm subpopulations in Iberian red deer epididymal sperm and their changes through the 24 cryopreservation process. Biol. Reprod. 72 316-327. 
1 Martinez-Pastor F, Johannisson A, Gil J, Kaabi M, Anel L, Paz P, Rodriguez-Martinez H,

2 2004: Use of chromatin stability assay, mitochondrial stain JC-1, and fluorometric

3 assessment of plasma membrane to evaluate frozen-thawed ram semen. Anim. Reprod. Sci.

$4 \quad 84121-133$.

5 Maxwell WMC, 1986: Artificial insemination of ewes frozen-thawed semen at a

6 synchoronized Oestrus. 1. Effect of time of onset of oestrus, ovulation and insemination on

7 fertility. Anim. Reprod. Sci. 10 301-308

8 Maxwell WMC, Hewitt LJ, 1986: A comparison of vaginal, cervical and intrauterine

9 insemination of sheep J.Agric.Sci.Camb. 106 191-193.

10 Maxwell WMC, Landers AJ, Evans G, 1995: Survival and fertility of ram spermatozoa

11 frozen in pellets, straws and minitubes. Theriogenology 43 1201-1210.

12 Maxwell, WMC, Nebel, RL, Lewis GS, 1996: .Survival and fertility of microencapsulated

13 ram spermatozoa stored at $5^{\circ} \mathrm{C}$. Reprod. Domest. Anim. 31 665-673.

14 Maxwell WMC, Salamon S, 1993: Liquid storage of ram semen: a review. Reprod. Fertil.

15 Dev. 5 613-638.

16 Maxwell, WMC, Stojanov, T, 1996: Liquid storage of ram semen in the absence or

17 presence of some antioxidants. Reprod. Fertil. Dev. 8 1013-1020.

18 Maxwell WMC, Wilson HR, Butter LG, 1983: Fertility of ewes after intrauterine

19 insemination with frozen semen. Proc. Departament of Agriculture Conference, South

20 Perth, Western Australia.

21 Moce E, Graham JK, Schenk JL, 2006: Effect of sex-sorting on the ability of fresh and

22 cryopreserved bull sperm to undergo an acrosome reaction. Theriogenology (in press).

23 Mortimer ST, Maxwell WM, 1999: Kinematic definition of ram sperm hyperactivation.

24 Reprod. Fertil. Dev. 11 25-30. 
1 Moses D, Martínez AG, Iorio G, Valcárcel A, Ham A, Pessi H, Castañón R, Marciá A, de

2 las Heras MA, 1997: A large-scale program in laparoscopic intrauterine insemination with

3 frozen-thawed semen in Australian Merino sheepin Argentine Patagonia. Theriogenology

$4 \quad 48651-657$.

5 Moussa M, Marinet V, Trimeche A, Tainturier D, Anton M, 2002: Low density

6 lipoproteins extracted from hen egg yolk by an easy method: cryoprotective effect on

7 frozen-thawed bull semen. Theriogenology 57 1695-1706.

8 Muller K, Pomorski T, Muller P, Herrmann A, 1999: Stability of transbilayer phospholipid

9 asymmetry in viable ram sperm cells after cryotreatment. J. Cell. Sci. 112 (1) 11-20.

10 Naqvi SMK, Joshi A, Bag S, Pareek SR, Mittal JP, 1998: Cervical penetration and 11 transcervical AI of tropical sheep (Malpura) at natural oestrus using frozen-thawed semen.

12 Small Ruminant Research 29 329-333.

13 Naqvi SMK, Pandey GK, Gautam KK, Joshi A, Geethalakshmi V, Mittal JP, 2005:

14 Evaluation of gross anatomical features of cervix of tropical sheep using cervical silicone

15 moulds. Anim. Reprod. Sci. 85 337-344.

16 Olesen I, 1993: Effects of cervical insemination with frozen semen on fertility and litter

17 size of Norwegian sheep. Livestock Production Science; 37 169-184.

18 Olds-Clarke P, Sego R, 1992: Calcium alters capacitation and progressive motility of

19 uterine spermatozoa from $+/+$ and congenic tw32/+ mice. Biol. Reprod. 47 629-635.

20 Ollero M, Perez-Pe R, Muino-Blanco T, Cebrian-Perez JA, 1998: Improvement of ram

21 sperm cryopreservation protocols assessed by sperm quality parameters and heterogeneity

22 analysis. Cryobiology 37 1-12.

23 O'meara CM, Hanrahan JP, Donovan A, Fair S, Rizos D, Wade M, Boland MP, Evans AC,

24 Lonergan P, 2005: Relationship between in vitro fertilisation of ewe oocytes and the 
1 fertility of ewes following cervical artificial insemination with frozen-thawed ram semen.

2 Theriogenology 64 1797-1808.

3 Park JE, Graham JK, 1992: Effects of cryopreservation procedures on sperm membranes.

4 Theriogenology 38 209-222.

5 Paulenz H, Soderquist L, Adnoy T, Nordstoga, AB, Andersen M, Berg K, 2005: Effect of

6 vaginal and cervical deposition of semen on the fertility of sheep inseminated with frozen-

7 thawed semen. Vet. Rec. 156 (12): 372-375

8 Paulenz H, Soderquist L, Adnoy T, Nordstoga A, Gulbrandsen B, Berg KA, 2004: Fertility

9 results after different thawing procedures for ram semen frozen in minitubes and mini

10 straws. Theriogenology 61 1719-1727.

11 Paulenz H, Soderquist L, Perez-Pe R, Berg KA, 2002: Effect of different extenders and

12 storage temperatures on sperm viability of liquid ram semen. Theriogenology 57 823-836.

13 Paz P, Melcón C, Sánchez AJ, Anel L, Anel E, Rodríguez C, García C, Herráez MP and

14 Chamorro CA, 2002: Glycoconjugates of frozen-thawed ram sperm evaluated by

15 microphotometry and acrosome status.Theriogenology 57696.

16 Pena FJ, Johannisson A, Wallgren M, Rodriguez-Martinez H, 2003: Assessment of fresh

17 and frozen-thawed boar semen using an Annexin-V assay: a new method of evaluating

18 sperm membrane integrity. Theriogenology 60 677-689.

19 Peris SI, Morrier A, Dufour M, Bailey JL, 2004: Cryopreservation of ram semen facilitates

20 sperm DNA damage: relationship between sperm andrological parameters and the sperm

21 chromatin structure assay. J. Androl. 25 224-233.

22 Raynal P, Houdeau E, 2004: Comparison of the uterine reflex activity during artificial

23 insemination and mating in the ewe. J.Gynecol.Obstet.Biol.Reprod. 33: 725-733.

24 Salamon S, Maxwell WM, 2000: Storage of ram semen. Anim. Reprod.Sci. 62 77-111. 
1 Salamon S, Maxwell WMC, 1995: Frozen storage of ram semen. I. Procesing, freezing,

2 thawing and fertility after cervical insemination. Anim. Reprod.Sci. 37 185-249.

3 Sancho M, Perez-Sanchez F, Tablado L, de Monserrat JJ, Soler C, 1998: Computer

4 assisted morphometric analysis of ram sperm heads: evaluation of different fixative

5 techniques. Theriogenology 50 27-37.

6 Sayre BL, Lewis GS, 1997: Fertility and ovum fertilization rate after laparoscopic or 7 transcervical intrauterine artificial insemination of oxytocin-treated ewes. Theriogenology $8 \quad 48267-275$.

9 Shackell GH, Kyle B, Littlejohn RP, 1990: Factors influencing the success of a large scale 10 artificial insemination programme in sheep. In proc: New Zeal. Soc. Anim. Prod. 50 42711430.

12 Sikka SC, 2004: Role of oxidative stress and antioxidants in andrology and assisted 13 reproductive technology. J. Androl. 25 5-18.

14 Stellflug JN, Wulster-Radcliffe MC, Hensley EL, Cowardin EA, Seals RC, Lewis GS, 15 2001: Oxytocin-induced cervical dilation and cervical manipulation in sheep: effects on 16 laparoscopic artificial insemination. J.Anim.Sci. 79 568-573.

17 Suh TK, Schenk JL, Seidel GE, Jr., 2005: High pressure flow cytometric sorting damages 18 sperm. Theriogenology 64 1035-1048.

19 Thomas CA, Garner DL, DeJarnette JM, Marshall CE, 1998: Effect of cryopreservation of 20 bovine sperm organelle function and viability as determined by flow cytometry. Biol. 21 Reprod. 58 786-793.

22 Valcarcel A, de las Heras MA, Perez L, Moses DF, Baldassarre H, 1997: Assessment of 23 the acrosomal status of membrane-intact ram spermatozoa after freezing and thawing, by 24 simultaneous lectin/Hoechst 33258 staining. Anim Reprod Sci. 45 299-309. 
1 Verstegen J, Iguer-Ouada M, Onclin K 2002: Computer assisted semen analyzers in

2 andrology research and veterinary practice. Theriogenology 57 149-179.

3 Vishwanath R, Shannon P, 2000: Storage of bovine semen in liquid and frozen state.

4 Anim. Reprod. Sci. 62 23-53.

5 van Wagtendonk-de Leeuw AM, Haring RM, Kaal-Lansbergen LM, den Daas JH, 2000:

6 Fertility results using bovine semen cryopreserved with extenders based on egg yolk and

$7 \quad$ soy bean extract. Theriogenology 54 57-67.

8 Watson PF, Martin IC, 1975: The influence of some fractions of egg yolk on the survival

9 of ram spermatozoa at 5 degrees C. Aust.J.Biol.Sci. 28 145-152.

10 Williams AC, Ford WC 2001: The role of glucose in supporting motility and capacitation

11 in human spermatozoa. .J. Androl. 22 680-695.

12 Windsor DP 1995: Factors influencing the success of transcervical insemination in Merino 13 ewes. Theriogenology 43 1009-1018.

14 Windsor DP, 1997: Mitochondrial function and ram sperm fertility. Reprod. Fertil. Dev. 9 $15 \quad 279-284$.

16 Windsor DP, Szell AZ, Buschbeck C, Edward AY, Milton JTB, Buckrell BC 1994:

17 Transcervical artificial insemination of Australian Merino ewes with frozen-thawed semen.

18 Theriogenology 42 147-157.

19 Windsor DP, White IG, 1993: Assessment of ram sperm mitochondrial function by 20 quantitative determination of sperm rhodamine 123 accumulation. Mol. Reprod. Dev. 36 $21 \quad 354-360$.

22 Wulster-Radcliffe MC, Lewis GS, 2002: Development of a new transcervical artificial 23 insemination method for sheep: effects of a new transcervical artificial insemination 24 catheter and traversing the cervix on semen quality and fertility.Theriogenology 581361 251371. 
1 Wulster-Radcliffe MC, Wang S, Lewis GS, 2004: Transcervical artificial insemination in

2 sheep: effects of a new transcervical artificial insemination instrument and traversing the

3 cervix on pregnancy and lambing rates. Theriogenology 62 990-1002.

4 Yaniz J, Marti JI, Silvestre MA, Folch J, Santolaria P, Alabart JL, Lopez-Gatius F, 2005:

5 Effects of solid storage of sheep spermatozoa at 15 degrees on their survival and 6 penetrating capacity. Theriogenology 64 1844-1851.

7

8 
Table 1.- Variation factors of AI fertility in the Churra breed (Anel et al., 2005).

\begin{tabular}{lccl}
\hline Variation factor & $\begin{array}{c}\text { Total } \\
44,448\end{array}$ & $\mathrm{AI}=$ & $\mathrm{AIV}$ \\
$\mathrm{n}=17,631$ & LAI $\mathrm{n}=26,817$ \\
\hline Insemination technique & $* * *$ & & $* * *$ \\
Farm & $* * *$ & $* * *$ & $* * *$ \\
Year & $* * *$ & $* * *$ & $* * *$ \\
Season & $* * *$ & $* *$ & $* * *$ \\
Age of ewe & $* * *$ & $* * *$ & $* * *$ \\
Lambing-AI interval & $* * *$ & $* * *$ & $* * *$ \\
Ram & $* * *$ & $* * *$ & $* * *$ \\
Technician & $* * *$ & $*$ & N.S. \\
Cumulative number of AI/ewe & N.S. & & insemination
\end{tabular}
AIV: vaginal-cervical insemination; LAI: laparoscopic artificial insemination N.S.: non significant $(\mathrm{P} \geq 0.05)$; *: significant effect $(\mathrm{P}<0.05)$; **: very significant effect $(\mathrm{P}<0.01) ; * *$ : highly significant effect $(\mathrm{P}<0.001)$. 
1 Table 2.- Length, external width and number of folds of the uterine cervix in several sheep breeds (Mean \pm SEM) (Kaabi, 2002).

\begin{tabular}{|llll|}
\hline Breed & Length (cm) & Width (cm) & $\begin{array}{c}\text { Number of cervical } \\
\text { folds (n) }\end{array}$ \\
\hline Assaf & $7.38 \pm 0.16^{\mathrm{a}}$ & $1.31 \pm 0.04^{\mathrm{bc}}$ & $4.63 \pm 0.14^{\mathrm{a}}$ \\
Merino & $7.09 \pm 0.13^{\mathrm{ab}}$ & $1.44 \pm 0.03^{\mathrm{a}}$ & $3.84 \pm 0.11^{\mathrm{b}}$ \\
Castellana & $6.89 \pm 0.15^{\mathrm{b}}$ & $1.37 \pm 0.04^{\mathrm{ab}}$ & $3.97 \pm 0.14^{\mathrm{b}}$ \\
Churra & $6.14 \pm 0.15^{\mathrm{c}}$ & $1.25 \pm 0.04^{\mathrm{c}}$ & $4.52 \pm 0.13^{\mathrm{a}}$ \\
\hline
\end{tabular}

3

Different superscripts within columns indicate significant differences $(P<0.05)$. 
Table 3.- Fertility according to type of insemination in Churra breed (synchronized oestrous, and semen cooled at 15 C) (Alvarez, 2000).

\begin{tabular}{|l|c|c|c|}
\hline Type AI $^{\mathbf{1}}$ & Fertility (\%) $^{\mathbf{2}}$ & $\begin{array}{c}\text { Absolute } \\
\text { frequency (n) }\end{array}$ & $\begin{array}{c}\text { Relative } \\
\text { frequency (\%) }\end{array}$ \\
\hline $\mathbf{0}$ & $22.22^{\mathrm{abc}}$ & 18 & 0.90 \\
\hline $\mathbf{1}$ & $28.21^{\mathrm{a}}$ & 677 & 32.60 \\
\hline $\mathbf{2}$ & $31.02^{\mathrm{ab}}$ & 980 & 47.20 \\
\hline $\mathbf{3}$ & $43.18^{\mathrm{c}}$ & 396 & 19.10 \\
\hline $\mathbf{4}$ & $16.67^{\mathrm{abc}}$ & 6 & 0.30 \\
\hline
\end{tabular}

${ }^{1}$ Type 0: vaginal deposition; Type 1: minimal penetration $(0.5 \mathrm{~cm}$ depth), total reflux; Type 2: $0.5-1 \mathrm{~cm}$ depth and partial reflux; Type 3: 1-2 cm depth and no reflux; Type 4: penetration to uterus and no reflux.

$5 \quad{ }^{2}$ Rows with different superscripts differ $\mathrm{P}<0.001$. 
1 Table 4.- Fertility variation (\%) based on insemination depth -synchronized oestrus, cooled semen-(Kaabi, 2002).

\begin{tabular}{|ll|}
\hline AI depth & Fertility (n) \\
\hline$\leq 1 \mathrm{~cm}$ & $48.08(287)^{\mathrm{a}}$ \\
$1 \mathrm{~cm}-2 \mathrm{~cm}$ & $64.29(182)^{\mathrm{b}}$ \\
$2 \mathrm{~cm}-3 \mathrm{~cm}$ & $65.12(43)^{\mathrm{b}}$ \\
$3 \mathrm{~cm}-4 \mathrm{~cm}$ & $31.25(208)^{\mathrm{c}}$ \\
$>4 \mathrm{~cm}$ & $29.41(68)^{\mathrm{c}}$ \\
Total & $\mathbf{4 6 . 7 0 ( 7 8 8 )}$ \\
\hline
\end{tabular}

3

Different superscripts in the same column indicate significant differences $\left(\chi^{2} ; P<0.05\right)$.

4 
1 Table 5.- Effects of cervical manipulation on fertility results for intrauterine laparoscopy AI -synchronized oestrus, frozen-thawed semen- (Kaabi, 2002).

\begin{tabular}{|lll|}
\hline Experimental group & N & Fertility (\%) \\
\hline Without cervical manipulation & 180 & $58.89^{\mathrm{a}}$ \\
Cervical manipulation between 0 and $3 \mathrm{~cm}$ & 23 & $60.87^{\mathrm{a}}$ \\
Cervical manipulation between 3 and $4 \mathrm{~cm}$ & 5 & $40.00^{\mathrm{ab}}$ \\
Cervical manipulation beyond $6 \mathrm{~cm}$ (intrauterine) & 151 & $47.68^{\mathrm{b}}$ \\
Total & $\mathbf{3 5 9}$ & $\mathbf{5 4 . 0 4}$ \\
\hline
\end{tabular}

Different superscripts in the same column indicate significant differences $\left(P<0.05 ; \chi^{2}\right)$ 


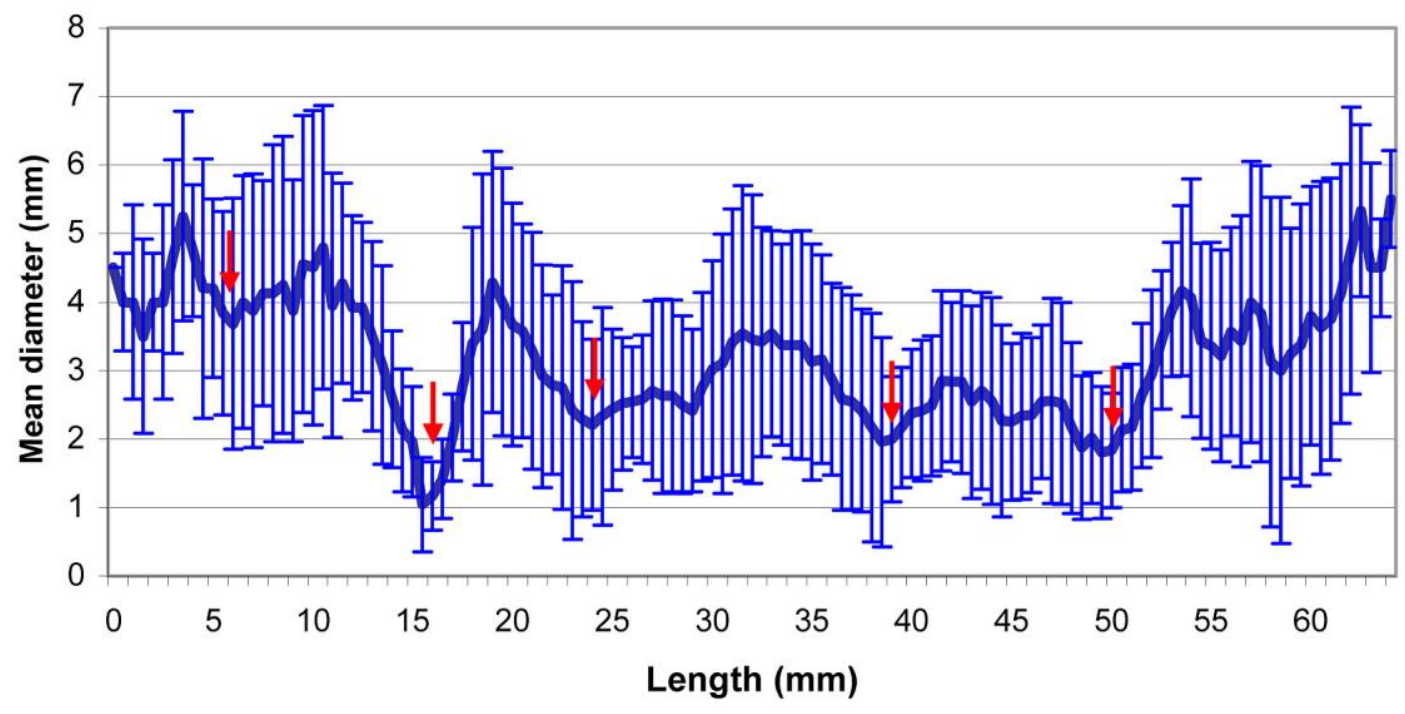

2 Figure 1.- Variation in the diameter of the cervical lumen (mean $\pm \mathrm{SD})$ along the cervical

3 length, according to nuclear magnetic resonance (Alvarez, 2000). Red arrows indicate the

4 position of cervical folds. 

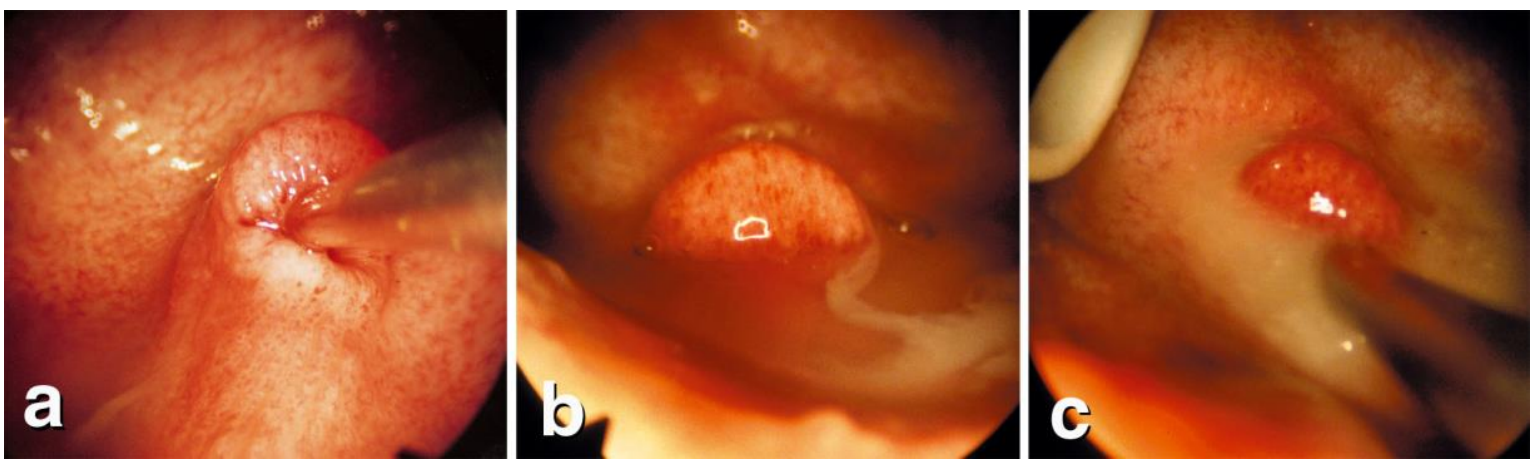

2

3 Figure 2.-.Seminal reflux in vaginal-cervical insemination: (a) without reflux, (b) partial

4 reflux and (c) total reflux.

5

6 

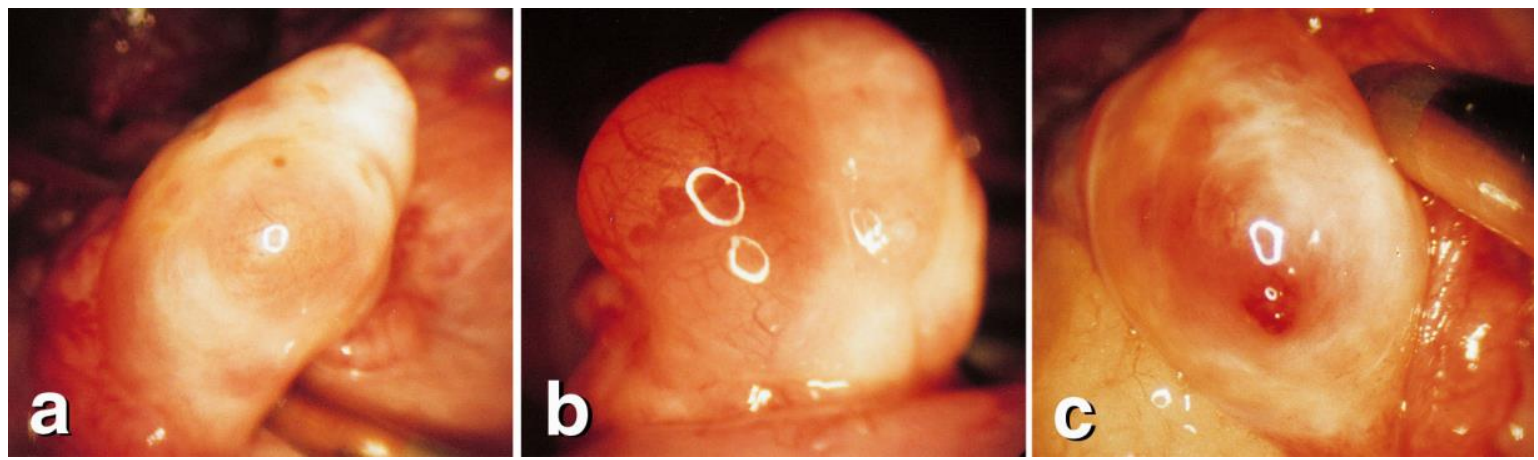

3

4 Figure 3.- Ovarian status observed by laparoscopy during intrauterine AI: (a) follicle; (b) 5 preovulatory follicle and (c) ovulated follicle. 


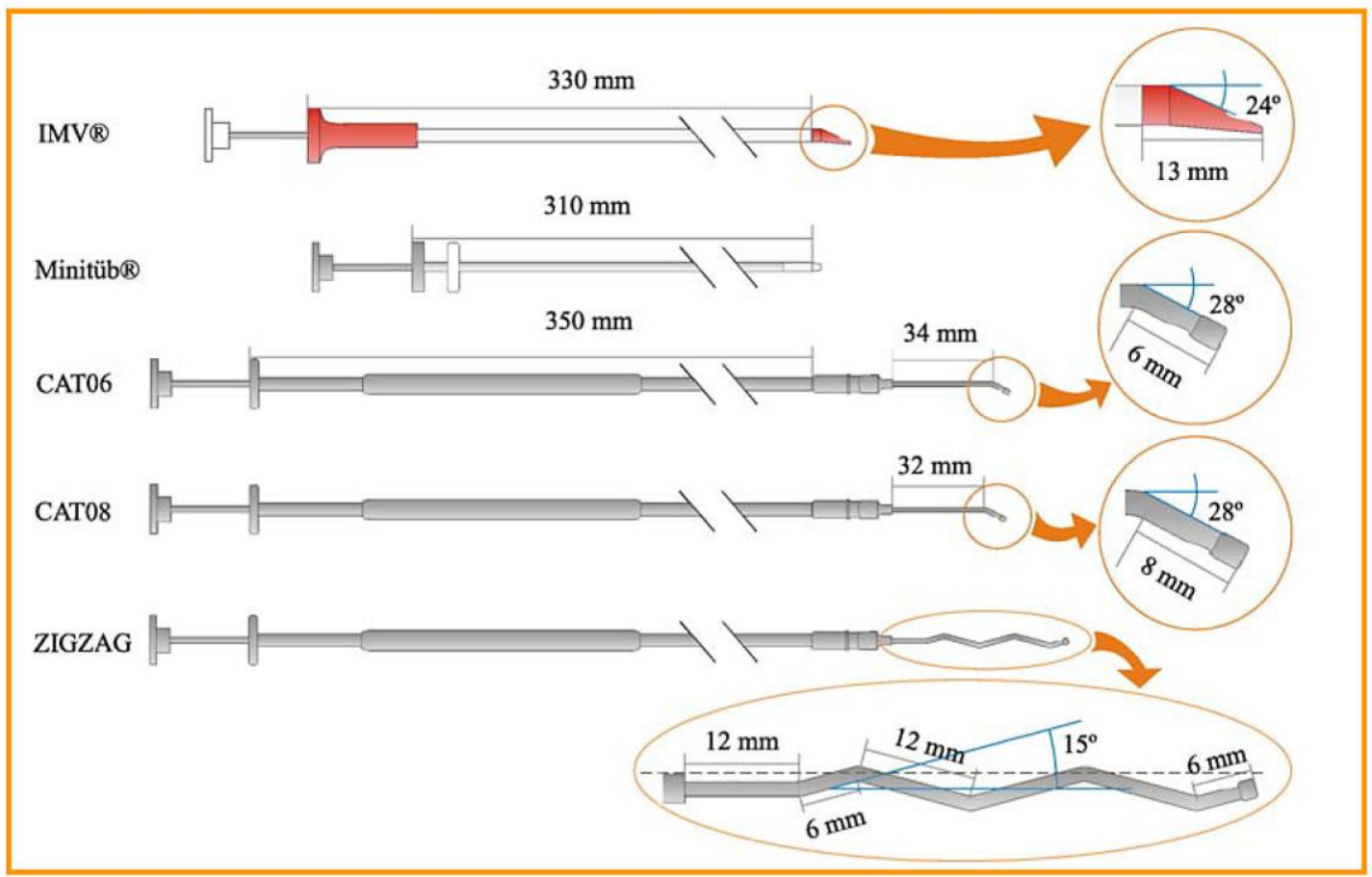

3

4 Figure 4.- Instrumental adaptations for transcervical Al in sheep: catheters tested by Kaabi, 2002

5 (CAT06, CAT08 and ZIGZAG were designed in the University of León).

6

7 


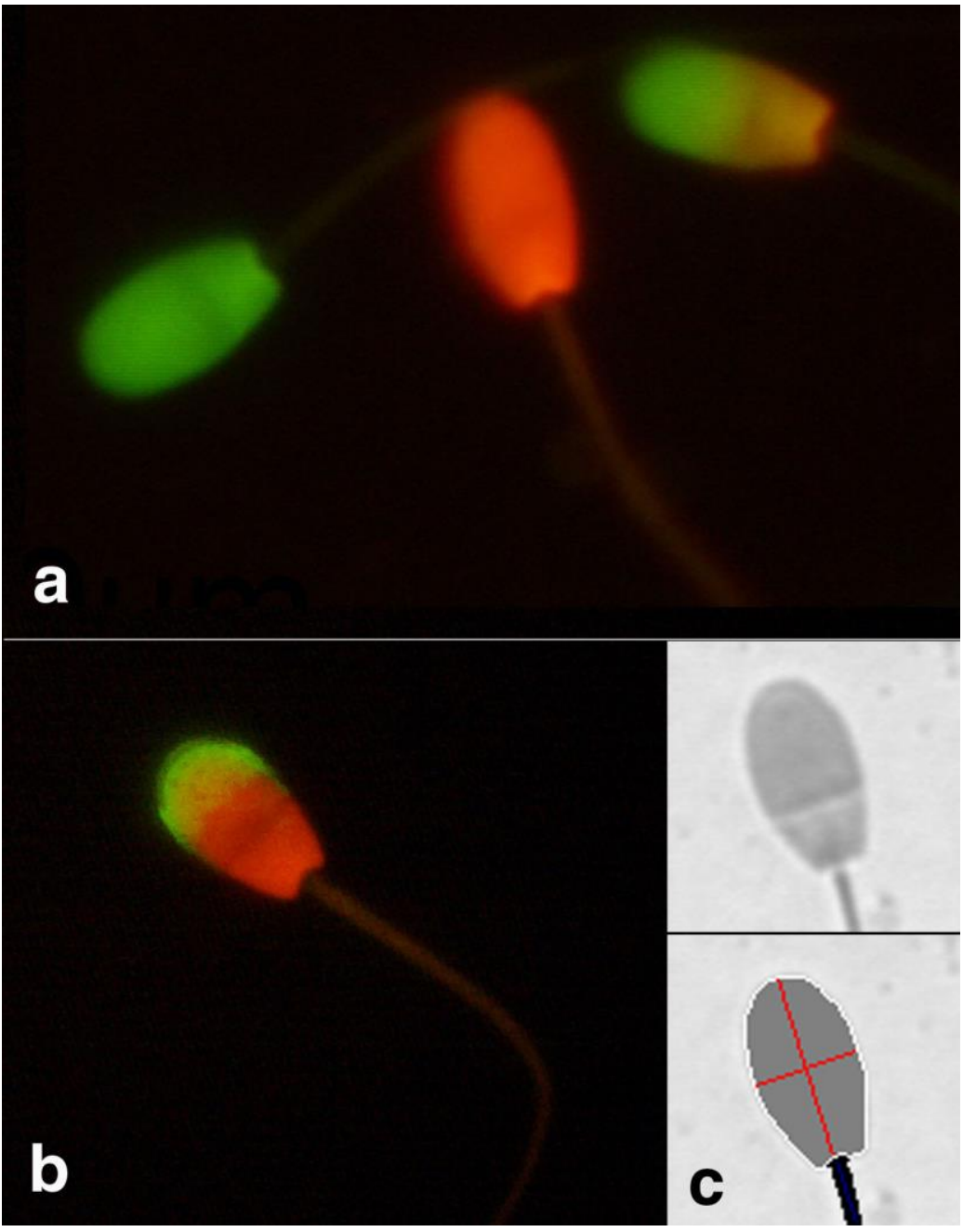

3

4 Figure 5.- Ejaculated ram spermatoza: a) double stain SYBR-14/IP: viable (green), dead

5 (red) and moribund (green+red), b) dead with damaged acrosome by double stain PNA-

6 FITC/ PI and c) microscopic image and its mask obtained by CASMA system. 